\title{
EdUCATION IN TIMOR-Leste: ENVISIONING THE
} FUTURE

\author{
Robin Burns ${ }^{\mathrm{a}}$ \\ Independent Education Consultant
}

\begin{abstract}
Timor-Leste is a small state that finally achieved independence in 2002. It has had to re-build an entire education system from a small base largely destroyed in the independence struggle. This paper presents the issues identified in pre-independence meetings, and considers these within the framework of transition and transformation problems for a small island with a diverse population and a long history of colonisation, using Namibia as an apt example. Fifteen years later, teacher preparation both pre-and in-service is identified as a major issue in achieving educational and social goals, with language training a key factor. Enrolments have improved and gender equity is close to parity, but urban-rural differences remain. Late enrolments, drop-outs especially in the early years, and repetition are major hurdles in achieving an educated, knowledgeable and qualified population.
\end{abstract}

Keywords: educational priorities, role of teachers, newly independent small state, Timor-Leste

\section{Introduction}

Education is held in high esteem as an instrument of social change and transformation. But education alone cannot bring about a new society and new relationships between citizens; that requires interactions throughout the society and its institutions. Nevertheless, education is considered a key factor in society, whether it is charged with fuelling "the knowledge economy" and the transformation from production to service industries in advanced capitalist societies, raising employment and income levels especially in developing countries, or healing a society that has been torn by conflict.

It is argued here that it is the kind of education and the way it is conceptualised as a means of social renewal that is critical, especially in a post-conflict situation. The case presented here is Timor-Leste, one of the newest nations on the world stage. It has emerged from nearly five centuries of colonisation: 450 years under Portuguese rule, and 24 years of harsh occupation by Indonesia. The Portuguese provided limited, elite education. Under Indonesia, mass basic education was attempted, with teachers imported in large numbers from Indonesia. In the three years between the Indonesian retreat in 1999 and full independence in May 2002, not only did a huge number of foreign teachers leave the country, but schools themselves were destroyed in the struggle. The newly independent government thus faced the task of re-building, from a very low base indeed. And it was not just educational institutions that were destroyed, so there is ongoing competition for resources for infrastructure, personnel and materials throughout society. In education, the need is as basic as providing water and sanitation for schools.

The weak base on which to build education, and the period when very little education took place, provides an opportunity to build a system appropriate for the present realities and future hopes and expectations. Thus education figured highly at anticipatory planning meetings of Timorese abroad as the end of Indonesian domination approached. This paper surveys educational directions proposed prior to independence, using educational development in a small state as the conceptual framework, and outlines present achievements and ongoing problems. Teacher preparation and support emerges as the key issue.

\footnotetext{
Correspondence can be directed to: rburns@netspace.net.au
} 


\section{Background}

The Democratic Republic of Timor-Leste (formerly East Timor), is a small island in the Timor Sea. Its nearest neighbours are Indonesia and Australia. It shares the island with Indonesian West Timor, and includes two tiny off-shore islands, and an enclave in West Timor. It is tropical, rugged and mountainous, and around 76 percent of people are subsistence farmers (Albergaria-Almeida and Martinho, 2015). The Timor Sea has rich gas and oil fields, the boundary being subject to dispute with Australia. The Petroleum Fund "is being used to promote human progress through the development of the non-oil economy" (Albergaria-Almeida and Martinho 2015, p.2365). The most recent population estimate is $1,212,000$, of whom 48 percent are under 15 . The birthrate is one of the highest in the world at 7.5 children per woman (Albergaria-Almeida and Martinho, 2015). The majority of people follow the Roman Catholic faith, and in addition to its strictures regarding birth control there is a concern to re-populate following the heavy loss of life during both struggles for independence. The population consists of a number of smaller groups with distinct dialects. During the Indonesian occupation, Bahasa Indonesia was the language of instruction in schools and in the wider public arena. Portuguese has been selected as the national language, side-by-side with Tetum, a Timorese lingua franca.

\section{Similar Issues Faced in Namibia}

Brock and Crossley (2013) demonstrate the vital role that comparative and international studies in education can play in the present globalised and telecommunications world. They promote critical examination of the impacts of international blueprints found in the World Declaration on Education for All and a Framework for Action, the Millennium Development Goals and their follow-up Agenda for Sustainable Development. Based on research and theorising on issues for small states, especially small island states, insights are obtained regarding the crucial role of the local milieu "in any analyses of education and social development" (Brock and Crossley 2013, p.388). And in the navigation of the possibilities and pitfalls of policy and practice transfer, important lessons can also be learned from comparative and international studies.

One small state that shared some colonial similarities is Namibia. In the planning stage for Timor-Leste, how Namibia approached educational development was arguably helpful for raising issues for critical attention. Like East Timor, it had two colonial rulers (Germany and South Africa), both of whom used education specifically for the domination and servitude of the indigenous population. It underwent a long and violent struggle for independence, and has an ethnically and linguistically diverse population of just over two million. One difference is its large landmass, with the population thinly scattered, largely due to aridity. Three years after independence, in order to activate the constitutional right to education, the government produced a Development Brief for Education, Culture and Training (MEC, 1993) outlining ways to link education and social development with the realities of the 1990 s and beyond.

The 1993 document notes that education is both an investment in human capital which, through its extension and improvement promotes development, and a basic human right. The former is a well-recognised rationale for education, though a potentially problematic one in that it can merely reinforce conformity to a repressive regime. The latter gains its significance when linked to the goal of creating an equitable society. In order to achieve this, it is believed that effective participation in adult life and in the national community requires that all are able to understand and communicate with each other. As with adequate nutrition and sound health, basic education is proposed as fundamental to individual and social wellbeing (MEC, 1993).

The Namibian policy states that education for all does not simply mean more schools and classes and high participation rates. Quantitative increase can simply lead to greater penetration of ideologies and further sorting of people into 'success' and 'failure' categories based on the old 
social order. This only perpetrates the status quo. What is needed is qualitative change. This needs to take contextual matters into account, including politics, values and interests.

A 2011 survey by UNICEF indicates that progress has been made towards universal primary education (now 98\%) and that gender parity in enrolment and retention has been achieved. However, survival rates have not improved and declined in some districts and for some years, while repetition rates have increased. The San people in particular are disadvantaged especially in provision of first language instruction, which is general for the first three primary years, after which the national language, English, is introduced, with first language instruction continuing but not always available. In a country that is inequitable (UNICEF, 2011), classrooms, equipment, and especially teacher preparedness remain issues of concern (Katjavivi, 2016; UNESCO, 2010/11).

Thus, issues of educational quality, the role of the context in which change is desired, language, resources and teacher education continue as key concerns for Namibia. Beginning afresh in TimorLeste, these point to issues to consider.

\section{Education and Social Transformation}

As a key aspect of social transformation, "new ways" are required "to think about education and training and how we organise it" (MEC 1993, p.4). However, one of the challenging aspects of education is that there is greater time lag between new ideas and policies, and new outcomes in education than in many other sectors, nor does change necessarily lead to the desired outcomes (Arnove and Dewees, 1991).

The dangers created by time lag are shown in the slow process of increasing equality through education, leading to pressures both internal and external that may be generated to divert education to more short-term ends, especially the creation of a small number of highly educated people. Such pressure may divert educational resources, or may alternately be used for more constructive solutions both to the need for highly educated people and the means to acquire them. The choice is essentially a political one, although it may be pushed in purely economic, human resource terms.

There are many forces that form a society, its institutions and the individuals within it. Recognition of key factors, and the articulation of clear, realistic goals as well as the underlying vision, are essential ingredients in the development of new educational policy to serve the aspirations of the people and the country's development objectives. Education can and indeed must be a vital element in this process of development; it cannot be isolated from the wider social reality and the vision towards which it is moving. A new regime may perpetuate old structures and processes, only the identity of those in power having changed, and any regime will impose its own vision and preferred means to achieve it (e.g. Carnoy and Samoff, 1990).

To create a vision for a democratic society, and the concrete steps towards its realisation, requires widespread community involvement. Democratic and development ideals require clear articulation in order to devise the appropriate policies for their implementation. In this process, education has a dual role. It plays a role in creating a new structure and relationships between people and government, different social groups, and people and the productive processes. As a cultural implement, it also plays a central role in spreading new ideologies, values and behaviours.

The transition to a new society is a difficult and exciting challenge. The following outlines educational issues for the effective realisation of the vision for a future Timor-Leste.

\section{Some Words about Scale}

In educational planning, policy and aid circles, the category small state has acquired some significance in recent years. A major element in this is the use of the notion of vulnerability as a characteristic of such states. Vulnerability in turn is seen as an exacerbated form of dependence (Atchoarena, 
1993; Bacchus and Brock, 1987; Bray, 1992; Brock and Crossley, 2013). Small states, defined as those with a population under 1.5 million, may face a particularly difficult balancing act between internal and external factors. In educational terms, "the central policy debate revolves around what it is both desirable and possible to undertake nationally, and what is appropriate and sensible to buy or use overseas" (Bray and Packer 1993, p.49). Commentators stress the importance of regional as well as wider links for such states, though there is a danger of new dependencies arising, and educational borrowing and transfer have been controversial issues throughout the post-colonial, globalised world. A small developing state will look for outside assistance, and regional links, posing both potential problems and possibilities, and in addition face internal fragmentation which poses different challenges to the emerging nation. Language will play a role in the choices made, especially regarding external alliances and regional membership; in turn, the choice of official and national languages may be partly determined by these external considerations. Combined with the role allocated to education, both will be central for promoting national identity.

A further aspect of small scale that has implications for education and is related to the generally less segmented economy and more ready links between sectors, is the crucial role for education in human resource development. Some commentators consider that small scale is an advantage in attempts to link education, human resources and development (Bray and Packer 1993, p.53). But while it is vital in any discussion of education and development to work towards economic growth and higher levels of employment, there are structural and political factors also to take into account. Thus, reasons for economic stagnation and high levels of unemployment need to be understood before appropriate planning can take place. And as the education policies of countries such as Namibia indicate, wider socio-political goals have often been the basis for change in the country's status and government. Such goals cannot be abandoned if the new government is to maintain its legitimacy. Therefore, decisions have to be made about balancing political and economic goals for education, e.g. between extending basic education to all and improving its quality, and accelerating specialist education for a technical and commercial elite.

And such decisions take place within a framework of educational globalisation led by the World Bank which has not only made structural adjustment policies a requirement for funding, but is exerting pressure on countries to improve the quality of education, to focus on basic education and to adopt measures aimed at increasing cost sharing in education. Since 1988 it has decided that structural adjustment in education has two forms: diversifying the sources of finance and containing unit costs (Nieuwenhuis 1996, pp.128-129). One may well ask where equity and democracy fit into such prescriptions.

Hindson (1995; see also Ball, 1998) aptly reminds us that there is a danger in assuming that educational planning models in use in western societies can simply be applied to produce comparable outcomes in other nations. This is applicable regardless of the size of the nation, and both at the level of developing educational plans and strategies, and also in the ways in which aid agencies and others evaluate the outcomes of such plans.

...orthodox Western-oriented planning models did not take into account the now generallyaccepted complexity of the interaction between education and development...The logical rational planning process has thus often been subverted by the impact of local tensions based in local cultural contexts and the results educational direction has not been authorised by the Western rational model. (Hindson 1995, p.327)

\section{Embarking on Education for Change}

The foregoing presents an overview of issues in the education-development nexus, and the contextualising of these within the realities of the late 1990s. The task for education in an independent 
Timor-Leste involves facing socio-economic and political realities, coupled with the enunciation of a philosophy and vision of both a desirable Timor-Leste, and a possible one. Only through testing such visions with the people, as widely as possible, and through involving them in the drawing up of detailed objectives, plans and strategies, will a policy and a praxis emerge that will bring together the whole community to move into the new future. The present provides significant restraints on that vision and the processes for its realisation, though change is an inherent capacity in all societies. The question is how to do it consciously, co-operatively and effectively. To quote from the late Paulo Freire,

The fundamental role of those committed to cultural action for conscientization is not properly speaking to fabricate the liberating idea, but to invite the people to grasp with their minds the truth of their reality. (Freire 1972, p. 76)

While this may seem almost utopian in a situation where the entire fabric of society was ruptured, the people of Timor-Leste have lived under foreign domination for so many generations, there is an opportunity at last for them to decide the shape and content of future institutions. Outside rule can unite people in the liberation struggle, but also create divisions that, once the ruler has gone, surface and disrupt. Shaping the new nation, and shaping education need to work hand in hand, with involvement of the people a key for both.

\section{A Suggested Agenda}

In the pre-independence situation, three central issues emerged:

1. Who shall be educated, and to what levels?

2. What type(s) of education?

3. The educators

A fourth, resources, finance and administration, is critical but beyond the scope of this discussion as these are issues that affect all public sectors. Expanding the first three issues, further considerations are:

\section{Who Shall be Educated, and to What Levels?}

\section{Equity: Interpreting Education for All}

By 1994 the literacy rate for those 10 years old and beyond was $47.3 \%$, a rise of $13 \%$ in 8 years. Approximately 150,000 students were recorded in all the levels of formal education (Mameo, 1995), but this gives no idea of the actual retention rates, success rates at different levels, nor distribution at each level by gender, ethnicity or location. Whichever way one interprets the figures, illiteracy is a key issue in Timor-Leste. And given the nature of the terrain, the long period of disruption caused by the occupation, and poverty, one can assume that not all of the relevant age cohorts even begin school. Equity begins with the question of access: how that is distributed by gender and location, among other factors, is a further question. Before any policy is enunciated, a realistic assessment of school provision, school enrolments and progression through the school system is essential. Reasons for non-attendance are also vital: in other situations where schooling has made little impact on the employment prospects of sectors of the population, especially in Africa, there has been a falling away not only of enrolments but of attendance (e.g. Namibia: UNICEF, 2011).

\section{Basic Education}

Basic education has become an orthodox item in educational planning in developing countries, actively promoted by the World Bank, and is often interpreted as an economic rather than a human rights issue. Namibia adopted a 10 year basic education plan which it aims to offer to all children; other countries have established 7 years as the basic framework, roughly corresponding to primary education. Questions here include: 
i. how many years basic education?

ii. should all children undergo the same content?

iii. how to ensure equity in quality of basic education?

iv. should it be free? if not, how should costs be shared?

v. will an upper limit be placed on age of entry?

vi. how to encourage hard-to-reach groups to attend, e.g. girls, ethnic minorities, remote area children?

\section{Post-Basic Education}

A major question here in addition to issues around provision, is entry qualifications. If basic education is defined as primary schooling, what proportion of primary completers are expected to continue? Will there be alternatives to an academic stream, and how will children be selected for each? More complex questions about qualifications, certification and the possibility of re-entry at a later stage through the development of flexible paths to different levels must also be faced, and given the small population of Timor-Leste, serious questions asked about the range of provision, especially at the tertiary level, that can reasonably be expected within the country.

\section{Youth}

Youth are a special challenge, and unemployment amongst secondary school leavers seems very high. The period of war has led to the disruption of schooling and school-employment pathways, if they ever existed clearly for the majority of Timorese youth. In addition to the usual problem of school drop outs and push outs, a pool of both literate and illiterate youth needs to be harnessed to the new national project. The Seychelles embraced a bold programme in the 1980s, building special youth villages for two years of work and development oriented schooling (Haffenden, 1991). In Botswana, and in an earlier phase in Tanzania, youth brigades have been formed to provide both (further) education for young people and to use the skills of school leavers in village communities, giving future social leaders experience of work in the rural areas and service in agricultural sectors (Flederman, 1991). In Nicaragua under the Sandinista government youth played a vital role in the successful national literacy campaign, a key post-liberation programme (Arnove and Dewees, 1991). Involving youth, empowering them especially where they have been silenced and subverted by illiteracy, and combining education with realistic job-creation is a central challenge for most nations, and a crucial one in Timor-Leste.

\section{Adults}

There are many educational challenges in a country where illiteracy rates increase with age, and where the majority of the indigenous population live in the rural areas. Literacy and post-literacy are linked factors in involving people in their community's and their nation's development. FRETILIN, a leftist political party in Timor-Leste recognised this in its Freirian-based literacy campaigns in the mid-1970s (Hill, 1978). Through Freire, particularly in Guinea-Bissau, literacy is proposed as a key item to liberate the bulk of the population from the 'culture of silence' to which illiteracy, and the reasons for that illiteracy, condemns them (Freire, 1978). While Freire's approach, which involves politicisation, activation and the development of critical skills for action and reflection, is idealistic, and requires extensive recruitment, training, organisation and maintenance, it also provides a basis for considering essential questions about the purpose and content of literacy work. A further issue to be addressed is the resources for post-literacy or literacy-maintenance, as well as how those newly awakened to the possibilities that education can bring, can use their skills in their communities. Freire's approach emphasises cultural circles rather than literacy groups as a way of emphasising 
the broad basis of such work. Despite the down-playing of the role of the teacher, this requires well organised and trained literacy workers and as was found in Guinea-Bissau, local organisational support, e.g. through the main political party, which may be problematically combined with equity issues in a divided Timor-Leste.

A related issue is one of adult education and training for those, presumably literate, who nevertheless require literacy maintenance, skills upgrading and further education to address changing economic circumstances. It is suggested that this is best provided at the workplace, though questions of responsibility, organisation and cost arise.

\section{What Type(s) of Education?}

\section{Curriculum Issues in Basic Education}

Central to consideration of education is the language of instruction. Language policy is a political issue, and it was decided that there would be two national languages: Tetum, and Portuguese. At the level of education there is nevertheless a question of initial language of instruction, and the timing of the introduction of additional languages. Gaining basic literacy in one's mother tongue is a sound beginning; given Timor-Leste's position in the Asian-Pacific region, the early introduction of English is also desirable. Malaysia is one example of a multi-lingual state which had an ambitious plan whereby students began their education in one of three nominated medium of instruction (MOI), i.e., Chinese, Malay or Tamil; at six months English was introduced for those for whom Bahasa Malaysia is the mother tongue, and Bahasa Malaysia was introduced for all others. After Year 1, English is added as a compulsory subject in national primary schools, where Malay is the MOI. Namibia introduces English in Year 4. Few teachers remain in Timor-Leste from either the Portuguese or Indonesian periods, when Portuguese and Bahasa respectively were the only languages of instruction. Therefore teacher preparation will be a vital task for successful educational development. The preparation and availability of education materials for teachers, and for students, is an additional huge and costly task. Namibia, for example, is still behind with both teacher and material development despite extensive efforts (UNICEF, 2011).

The content of general education is another area for decision-making. In most newlyindependent countries there is an urgent need for localisation of the curriculum: learning our history and geography, our environment, is a critical tool for involvement in our development, but it is also a starting point for moving out. There was a long debate in education in the 1980 s about 'relevant' education, especially for the immediate environment. Valuing local history, culture, knowledge and skills is an important part of the task of national development, and in meeting others and valuing their history and culture, too, in fact it is a key element in the development of unity and a multicultural society. However, parents often cite as a reason for sending children to school the need to know about the wider world, and the general conclusion of the relevance debate was that it had at best limited impact on development, nor was it an appropriate vehicle for the rectification of social and economic ills (Sinclair and Lillis, 1980). Curriculum is not a panacea, and widespread consultation regarding its content, as well as equivalent attention to the methods of imparting knowledge, are crucial for enabling education to play an active role in development, social, cultural and individual.

There has also been an extensive debate about the role that work should play in education at all levels. While it is now criticised as being one way to condition children to their pre-ordained place in the world, defining unemployment as a skills rather than a structural problem (Kraak, 1991), for many radical educators education cannot be meaningfully divorced from work if it is to avoid being purely elitist and theoretical. Study-service schemes proliferated from the late 1960s in an attempt to deal with this (Burns, 1978). They were designed to orient the participants to work, and for them in turn to influence formal schooling in the direction of more relevance to basic needs in society (Haffenden, 1991). Despite such innovations, how to relate schooling and work remains 
both a conceptual and a practical issue within education. Preparation, supervision, de-briefing and funding are central issues.

\section{Vocational Education}

Like relevance education, this has been a controversial issue in many developing countries. (e.g. Watson, 1994). A small country cannot afford a proliferation of training institutions and programmes, and the evidence suggests that parents and students alike are reluctant to commit themselves to what is often seen as an inferior option (Baker, 1989). How to provide appropriate training for the labour market depends on the development of that market, and the recognition of the time lag between delineation of a need for particular skills and its provision through education and training. On-the-job training, with appropriate development of a system of assessment and recognised qualifications, is an attractive option to institution-building. Again, training, supervision and evaluation of the trainees is an issue.

\section{Non-Formal Education}

Non-formal education is linked to vocational education on the one hand, and post-literacy on the other. Surveying existing provision, needs and likely providers, and the training and co-ordination of the latter, are required to extend learning opportunities to those previously deprived, and to those requiring further education for a changing workplace. As Youngman (2003) points out, literacy programmes sometimes reproduce existing inequalities. Non-formal education can be a key part of ongoing political education, and of personal development, including language learning. Local level study circles provide a useful approach, with considerable local input not only to the teachinglearning process, but to resourcing it e.g. through sharing facilities with schools, and recognising and using local skills and knowledge.

\section{Teacher Education}

Most accounts of education in newly independent countries, and increasingly throughout the world, focus first and foremost on the teachers as the key players in the process of educational delivery and change. On the one hand they constitute an interest group who may be very committed to existing policies and practices, and hence a key force for resistance to new ideas and practices, and on the other, the key to change. Beeby (1966) recognised four stages in the growth of a primary school system, based on the types of goals and organisation of the school as well as the level of teacher education. The second and third stages are formal and restrictive, with meaning and understanding not stressed until the final stage is reached, when teachers are well-educated and trained. The question therefore arises, how to transform the expectations inculcated during earlier phases? This in turn raises the wider issues of transformation of an education system as a whole. If it is not begun at the very early stages of education, then time and effort are surely wasted in the need to unlearn at a later stage. And given high drop-out rates in particular, the outcome of such a divided system is the creation of a hierarchy of learners not only with different amounts of formal education, but different experiences depending on the level they reach.

Projects to change and upgrade the teaching service are often only partially successful. The preservice level is one clear case for action, but this will take time both to alter entrance standards and qualifications, and for change to reach the classroom. Attracting appropriate students, and retaining them both in the course and in employment in education, may depend on the perception of education as a community value and as a respected form of employment with adequate remuneration and status as teaching is one occupation which is readily useable in other fields and can result in a high teacher turnover. Innovative approaches to recruitment can include recognition of other relevant 
experience in lieu of formal qualifications, community nomination to insure acceptance of the teacher in the community, especially if a strong community basis for the school is to be established and involvement of the community in the curriculum. Such approaches however require adequate on-the-job training and support. Innovative approaches to education or even adequate curriculum delivery will not come from poorly qualified, inexperienced teachers.

At the in-service level, locally delivered programmes are effective especially with support from the head teacher. Shorter courses tend to have little lasting effect, and the recognition of participation is important in teacher involvement. Nowhere is teaching an easy job; in a system disrupted, undergoing change, and with pupils and parents questioning the value of education given the high level of youth unemployment, teachers need to confidence in their ability to adapt to work with new methods and curricula (Bishop, 1986; Duggan, 1996; Duncan and Löfstedt, 1981; Maclure, 1994; and MEC, 1993).

In turn, the teacher educators cannot be ignored in any programme of in-service. It may seem a luxury in view of the many urgent needs in the education system to focus at this level, however, they are key players in the whole game, since they provide the human resources and models for others and for the system at every level.

\section{Fifteen Years on}

The task of educational maintenance, let alone reform, is a challenging one, and few countries can have faced the huge task that confronted newly-independent Timor-Leste. The question of resources looms very large, not just the money to pay for school buildings, equipment and teachers' salaries, but for upgrading and retraining, as well as the provision of language materials, and of books and magazines for the newly literate. In 1999 I suggested, following Freire, (1974) that decision-making and planning would not only "require(s) the development of an especially critical, flexible spirit" but the acceptance that "education becomes a highly important task" (pp.7-8).

The importance of education has been clearly accepted within the government's policy and planning statements. The emphasis in these statements is on education for the training of human resources for development (DRET, 2009). These documents state the importance of reforming education in order to improve its quality. Such improvement is vitally required for the achievement of any substantive educational change, since teachers are a key factor and their low educational base is a major barrier to their active, informed participation in educational reform. Similarly, Namibia has re-affirmed the need for "continuous improvement in quality teaching and learning outcomes" while highlighting the role of education in ongoing national development (Ministry of Education, 2011, p.iv).

Dealing in turn with the major areas outlined above:

\section{Who Shall be Educated and to What Level?}

Recent surveys show that while the highest repetition and dropout rate is at Grade 1 , it continues throughout primary school and has risen not decreased in the period surveyed (UNESCO, 2015). Indonesia accepted universal primary education as a priority but critics note that its aim was the "Indonesianization" of the population (Albergaria-Almeida and Martinho, 2015, p.2368). The present government has accepted universal primary education as a goal and made nine years of basic education compulsory, using a six-three structure. It is also free. However, the government is not the only educational provider and information about the private institutions is not readily available. The 2014 National Education Profile Update (Education Policy and Data Center, n.d.) shows that $18 \%$ of children aged $6-11$ and $23 \%$ of $12-17$ year olds were out of school. Interpreting these figures is further complicated by the fact that a considerable proportion of children start after 
age 6 , there are high repetition rates especially from the first to the second year, and high dropout rates though these decrease by the upper secondary level. A significant percentage of enrolments of 12-17 year olds could still be at the basic level. Enrolments also vary between urban and rural areas. Enrolments alone do not indicate student achievement, e.g. the achievement of literacy in either national language is slow.

For national sustainable development goals to be achieved, rising educational standards and achievements are necessary. There is greater retention in the upper three secondary levels but only $25 \%$ of students progress to these schools, which are all in urban areas. Gender parity has been largely achieved though there are district variations, as in other demographic characteristics (UNESCO, 2015).

Prior to independence, tertiary students were sent to Indonesia, or made their way to Australia or other developed countries. There is now a national university in Dili, the capital, and a range of other post-school training centres, the latter all operated by private providers. Information on fees is not available but can be assumed to limit participation even further than the academic problems to reach that level.

\section{What Type of Education?}

The decision to make Portuguese as well as Tetum a national language follows its suppression during the Indonesian occupancy. A major challenge is the provision of teachers fluent in Portuguese, vital not just for language instruction but the entire curriculum. There are serious problems in the provision of a trained teaching workforce, right down to high absenteeism among teachers especially in the basic years. No matter how good the curriculum is, it is dependent on teachers for its implementation. Portugal is a major donor for education, and assists with provision of Portuguese teaching materials and teacher training. Resources for every aspect of education is a general problem for educational development in a newly emerging nation. But outside aid may come at the price of externally determined priorities and content (Brock, 2014; Crossley, 2001; Cummings, 1997; King and Palmer, 2014; and Torres, 1999). There is no space here to discuss curriculum content other than language.

The post-basic level has been divided into two streams, with a core of eight subjects (Tetum, Portuguese, English, Indonesian, Citizenship and Social Development, Multimedia Technologies, Religion and Moral Education, and Physical Education and Sport, the latter dropped in the final year). The two streams are Science and Technology, and Social Sciences and Humanities. Both are heavily academic in orientation. This re-structuring is being assisted by the Portuguese University of Aveiro, and includes provision of student and teacher materials, and teacher in-service (Almemida et al., 2014).

Vocational education is diverse, and non-formal education largely consists of adult literacy and short-term programmes by non-governmental organisations (NGOs).

\section{Teacher Education}

This is the crux for delivery and transformation of education at every level and is the most problematic aspect of education in Timor-Leste today. Following independence, volunteer teachers were recruited, many with only primary education and no teaching qualifications. There is still a significant need for Portuguese language training, many teachers reverting to Tetum or local dialects (Lucas et al., 2015). This lack affects their ability to deliver the curriculum, and to undertake training in subject fields. Additionally, they are dealing with large class sizes, and a variety of pupil ages in any one grade, infrastructure that is uneven at best, and a lack of organisational skills at every level of the education and administrative system. A useful recent project is the evaluation of secondary educational changes (Almemida et al., 2014). Evaluation of implementation of educational programmes at every level is often neglected; its use is needed for future planning and resourcing in Timor-Leste. 
In-service education for teachers is playing an important role, though it can contribute to teacher absenteeism. The University of Aveiro uses an innovative approach, starting with in-servicing the teacher educators, and empowering teachers who have gone through their programme to themselves become in-service leaders. Support for language training through periods in Portugal is also provided (Lucas et al., 2015).

\section{Discussion and Conclusion}

More than 25 years after independence Namibia is still facing a number of the problems now confronting education in Timor-Leste, in particular lack of teacher quality especially in remote areas, poor school infrastructure, and varying retention rates depending on level and location. It now spends $8 \%$ of its budget on education and is committed to educational improvement at all levels. The most salient lesson from this is the long, slow process of educational change and the need for ongoing commitment to that. Independent Timor-Leste is addressing many of the educational issues raised in pre-independence discussion, enshrining them in its policy and plans. Teachers are critical for achieving development throughout society and with the huge teacher loss in 1999 (Almemida et al., 2014), the system had to be re-constructed from a very low base. The collaboration with Portugal is productive in this process.

Competition with other institutions both for money and personnel is endemic but by no means unique to Timor-Leste. Nor are other key issues: overcoming the effects of rural isolation, ethnic diversity and income disparities in educational provision, enskilling of teachers for the challenges now and in the future, and improving educational content and outcomes. Timor-Leste may not yet be at the stage envisaged by Brock and Crossley (2013) where it can enjoy the advantages of small scale. Nevertheless, the vision for education is clear:

In 2030 the people of Timor-Leste will be educated, knowledgeable and qualified to live long and productive lives, respectful of place, family and positive traditional values. All individuals will have the same opportunities for access to quality education that will allow them to participate in the economic, social and political development process, ensuring social equity and national unity (Ministry of Education, 2011b).

Enabling the population, especially the rising generation, to realise this vision is an ongoing challenge. It is one which the nation has embraced and with goodwill can move towards.

\section{Notes}

Warm thanks are offered to Professor Michael Crossley and the late Professor Colin Brock for stimulating discussions over many years of issues raised here.

\section{References}

Albergaria-Almeida, P., Martinho, M. and Cabrita, I. (2014). Evaluating the Impact of Restructuring Secondary Education in East Timor. Procedia - Social and Behavioral Sciences 141: 665-669. Available at www.sciencedirect.com. [Accessed 6 February 2017].

Albergaria-Almeida, P. and Martinho, M. (2015). The Empowerment of Education in East Timor through In-Service Teacher Training. Procedia-Social and Behavioral Sciences 191, 2364-2368. Available at www.sciencedirect.com. [Accessed 6 February2017].

Arnove, R.F. and Dewees, A. (1991). Education and revolutionary transformation in Nicaragua, 19791990. Comparative Education Review, 35(1), pp. 92-109.

Atchoarena, D. (1993). Educational Strategies for Small Island States. Paris: Unesco International Institute for Education Planning. 
Bacchus, K. and Brock, C. (1987). The Challenges of Scale. London: Commonwealth Secretariat.

Baker, V.J. (1989). Education for its own sake: The relevance dimension in rural areas. Comparative Education Review, 33(4), pp. 507-518.

Ball, S.J. (1998). Big policies/small world: An introduction to international perspectives in education policy. Comparative Education, 34(2), pp. 119-130.

Beeby, C.A. (1966). The Quality of Education in Developing Countries. Cambridge Mass.: Harvard University Press.

Bishop, G. (1986). Innovation in Education. London: Macmillan.

Bray, M. (1992). Education Planning in Small Countries. Paris: UNESCO.

Bray, M. and Packer, S. (1993). Education in Small States: Concepts, challenges and strategies. Oxford: Pergamon Press.

Brock, C. (2014). Global curricular legacies and challenges for the twenty-first century. Journal of International and Comparative Education, 3(1), pp. 126-138.

Brock, C. and Crossley, M. (2013). Revisiting scale, comparative research and education in small states. Comparative Education, 49(3), pp. 388-403.

Burns, R. (1978). Education and development: Study-service programmes in the Philippines. Paper presented at the Asian Studies Association of Australia National Conference, Sydney.

Carnoy, M. and Samoff, J. (1990). Education and Social Transition in the Third World. Princeton N.J.: Princeton University Press.

Crossley, M. (2001) Cross-cultural issues, small states and research: Capacity building in Belize. International Journal of Educational Development, 21(3), pp. 217-229.

Cummings, W.K. (1997). The limits of modern education. In E. R. Beauchamp (Ed.), Comparative Education Reader. New York/London: RoutledgeFalmer, pp. 277-297.

DRET (Democratic Republic of East Timor). (2009). The Millennium Development Goals, Timor-Leste: Timor-Leste national report. Dili: Democratic Republic of East Timor.

Duggan, S. J. (1996). Education, teacher training and prospects for economic recovery in Cambodia. Comparative Education, 32(3), pp. 361-376.

Duncan, W. and Löfstedt, J.I. (1981) .The Swedish Free Church School Building Project and Teacher Training Project. Stockholm, Institute of International Education: Stockholm University.

Educational Policy and Data Center (n.d.). Timor-Leste. National Education Profile 2014 Update. Available at www.epdc.org/sirtes/default/files/documents/EPDC\%20NEP_Timor\%20Leste. pdf. [Accessed 5 February 2017].

Flederman, P. (1991). Tirelo Setshaba: Botswana's national study service scheme. In K. Evans and I.G. Haffenden (Eds.), Education for Young Adults. International Perspectives. London/New York: Routledge, pp. 108-117.

Freire, P. (1972). Cultural Action for Freedom. Harmondsworth: Penguin.

Freire, P. (1974). Education: The practice of freedom. London: Writers and Readers Publishing Cooperative.

Freire, P. (1978). Pedagogy in Progress. The Letters to Guinea-Bissau. New York: The Seabury Press (Translation: C. St. J. Hunter).

Haffenden, I.G. (1991). The Seychelles national youth service 1981-86: Curriculum innovation, implementation and purification. In K. Evans and I.G. Haffenden (Eds.), Education for Young Adults. International perspectives. London/New York: Routledge, pp. 128-137.

Hill, H. (1978). Fretilin: The origins, ideologies and strategies of a national movement for East Timor. Melbourne: Department of Politics, Monash University MA dissertation (unpublished).

Hindson, C. E. (1995). Education planning in Vanuata - an alternative analysis. Comparative Education, 31(3), pp. 327-337.

Katjavivi, P.H. (2016). Educational Transformation in Namibia. Address at the London Forum of the Commonwealth Council on Education.

King, K. and Palmer, R. (2014). Development assistance for education post-2015. Journal of International and Comparative Education, 3(1), pp. 139-152. 
Kraak, A. (1991). Making the hidden curriculum the formal curriculum: Vocational training in South Africa. Comparative Education Review, 35(3), pp. 406-429.

Lucas, M., Cabrita, I. and Ferreira, A. (2015). Pathways to Change: Improving the Quality of Education in Timor-Leste. Procedia - Social and Behavioral Sciences 186, 732-738. Available at www. sciencedirect.com. [Accessed 6 February 2017].

Maclure, R. (1994). Misplaced assumptions of decentralization and participation in rural communities: Primary school reform in Burkina Faso. Comparative Education, 30(3), pp. 239-254.

Mameo, D. (1995). Analysis of the development process in East Timor: Background, achievements, problems and alternatives. In de Sousa, Saldanha, J. M. (Ed.), The East Timor Project-Volume 1. Darwin: Northern Territory University Centre for Southeast Asian Studies, pp. 49-62.

MEC (Ministry of Education and Culture, Namibia). (1993). Toward Education for All. A development brief for education, culture and training. Windhoek: Gamsberg Macmillan.

Ministry of Education. (2011). Strategic Plan 2012-2017. Windhoek: Ministry of Education.

Ministry of Education. (2011b). National Education Strategic Plan 2011-2030. Dili: Ministry Of Education. Available at www.moe.gov.tl/pdf/NESP2011-2030.pdf. [Accessed 10 February 2017].

Nieuwenhuis, F. J. (1996). The Development of Education Systems in Postcolonial Africa: A study of a selected number of African countries. Pretoria: HSRC.

Sinclair, M. E. and Lillis, K. (1980). School and Community in the Third World. London: Croom Helm.

Torres, R.-M. (1999). Improving the quality of basic education? The strategies of the World Bank. In E.R. Beauchamp (Ed.), Comparative Education Reader. New York/London: RoutledgeFalmer, pp. 299-328.

UNESCO. (2010/2011). World Data on Education, $7^{\text {th }}$ ed. Available at www.ibe.unesco.org/en/document/ world-data--education-seventh-editition-2010-2011. [Accessed 10 February 2017].

UNESCO. (2015). Education for All 2015 National Review Report: Timor-Leste. Available at unesdoc. unescao.org/images/002290/229880E.pdf. [Accessed 16 February 2017].

UNICEF. (2011). Improving Quality and Equity In Education In Namibia: A Trend And Gap Analysis. Available at UNICEF_2011_Ninnes_Trends_and_Gaps_final_combined.pdf. [Accessed 16 February 2017].

Watson, K. (1994). Technical and vocational education in developing countries: Western paradigms and comparative methodology. Comparative Education, 30(2), pp. 85-97.

Youngman, F. (2003). The state, adult literacy policy and inequality in Botswana. In E. R. Beauchamp (Ed.), Comparative Education Reader. New York/London: RoutledgeFalmer, pp. 139-161. 
